\title{
Tighter formed staples produce stronger sealing against luminal leakage
}

\author{
Dwight D Henninger ${ }^{1}$, Jason Jones ${ }^{1}$, Jeffrey W Clymer*1 \\ ${ }^{1}$ Ethicon, Inc., Cincinnati OH, USA
}

\begin{abstract}
Background: Although the overall rate of anastomotic leakage in gastrointestinal surgery is low, there is still room for improvement via advances in medical or procedural care. The Proximate TLC Linear Cutter offers design advantages intended to produce more secure tissue apposition and reduce the occurrence of leakage. This study was performed to evaluate leak pressure for TLC and compare to another commercially-available stapler.

Methods: Applications were performed with both devices in ex vivo canine small intestine. Minimum leakage pressures were determined via a computer-controlled liquid pressure system. Staple height was also measured, and staple quality was evaluated on a five-point scale.

Results: Mean luminal leak pressure for TLC was $52 \%$ higher $(\mathrm{p}<0.001)$ and the proportion of luminal leakage occurring below $50 \mathrm{~mm}$ Hg was $82 \%$ lower $(\mathrm{p}=0.013$ ) relative to the comparator device. Mean height of formed staples was significantly lower for TLC ( $\mathrm{p}<0.001)$. No malformed staples were observed for either device.

Conclusion: In this relatively thin tissue model, both devices were capable of forming high quality staples. However, the Proximate TLC Linear Cutter produced more tightly formed staples and yielded both higher leak pressures and lower rates of leak at physiologically-relevant pressures. Clinical studies are necessary to confirm the results presented here.
\end{abstract}

\begin{abstract}
Abbreviations: GIA: DST GIA8038S Linear Cutter; NSAID: non-steroidal anti-inflammatory drug; TLC: Proximate TLC75 Linear Cutter
\end{abstract}

\section{Introduction}

Surgical staplers have become a mature technology, offering greatly increased speed in comparison to hand suturing, while producing secure apposition even in difficult-to-access locations [1]. However, several areas for improvement remain, notably reducing the rate of anastomotic leakage. For example, colorectal leak rates are reported to vary between 1 and 20\% [2,3] and associated mortality rates can be disturbingly high. Many patient-related risk factors for leakage have been identified, such as male gender, diabetes, smoking, steroid or NSAID use, and other comorbidities. Device-related risk factors are less well-defined, but may include amount of tissue tension, malformed staples, intersecting staple lines and number of firings. Clearly any improvement in stapler design that would reduce the chance of leakage or improve the security of the anastomosis would be of great advantage to the patient and surgeon.

The Proximate TLC Linear Cutter (Ethicon, Inc.) is designed with a unique cam mechanism and tissue retention pin to help reduce staple line leakage. The cam, located at the base of the device, forces the distal tip downward when firing begins, allowing for uniform pressure throughout the anvil and controlled tissue compression, ensuring a consistent staple line.

This ex vivo study was undertaken in order to evaluate the leakage from TLC and compare its performance to another commerciallyavailable linear cutter. An intestinal tissue model was chosen to measure the pressure required to produce luminal leakage at the staple line after application of the devices. We also examined formed staple height and staple form quality to determine whether these factors were directly related to leakage security.

\section{Methods}

Models similar to the one used here have been previously applied to evaluate the strength of anastomoses in pigs [4,5] and dogs [6]. We prefer to use canine tissue because it is thicker than that from porcine and closer in dimension to human. The small intestine samples were in the thickness range considered appropriate for the cartridges used.

Devices evaluated are given in Table 1. The TLC and GIA devices used in this study are both indicated for applications in gastrointestinal, gynecologic, thoracic, and pediatric surgery for transection, resection, and the creation of anastomoses, for use on tissue that can be compressed without excessive force to $1.5 \mathrm{~mm}$ thickness. Both devices use B-staples in 4 rows with an interposed knife blade to transect the tissue, and both devices were used to deliver staples of similar height intended for use in similar tissue ranges. Segments of harvested canine small intestine, 10 to $15 \mathrm{~cm}$ in length, with wall thickness ranging from 1.3 to $2.1 \mathrm{~mm}$ as measured by a Tissue Measuring Device $\left(8 \mathrm{~g} / \mathrm{mm}^{2}\right.$ for 15 seconds) [7] were instrumented for stapling and leak testing. Briefly, each end of the bowel segment was cannulated with an appropriately sized adaptor. Following the manufacturer's Instruction for Use, the device was applied and fired on the mid-point of the bowel tissue

Correspondence to: Jeffrey W Clymer, Ethicon, Inc., 4545 Creek Rd, Cincinnati OH 45242, USA, Tel: 513 337-3318,E-mail: jclymer@its.jnj.com

Key words: anastomotic leakage, linear cutter, stapler, staple height, staple form

Received: March 05, 2017; Accepted: March 24, 2017; Published: March 27, 2017 
Table 1. Devices evaluated for luminal leak pressure.

\begin{tabular}{|c|c|c|c|}
\hline Abbreviation & Product Name & Cartridge & Manufacturer \\
\hline TLC & $\begin{array}{c}\text { Proximate TLC75 } \\
\text { Linear Cutter }\end{array}$ & $\begin{array}{c}\text { TCR75 Blue } \\
\text { Cartridge }\end{array}$ & $\begin{array}{c}\text { Ethicon, Inc., } \\
\text { Cincinnati OH }\end{array}$ \\
\hline GIA & $\begin{array}{c}\text { DST GIA8038S } \\
\text { Linear Cutter }\end{array}$ & $\begin{array}{c}\text { GIA8038L Blue } \\
\text { Cartridge }\end{array}$ & $\begin{array}{c}\text { Medtronic, } \\
\text { Minneapolis, MN }\end{array}$ \\
\hline
\end{tabular}

segment, i.e., stapled and cut. A pre-compression period of 15 seconds was used prior to firing the devices. Each of the two resulting segments was designated as the right or left side of the firing from the operator's perspective with the anvil of the stapler facing upward.

Each sealed bowel segment was attached to and tested on a computer-controlled pressure system. The system infused water dyed with food coloring via the adaptor into the segment, increasing the intraluminal fluid pressure in $10 \mathrm{~mm} \mathrm{Hg}$ increments starting at $20 \mathrm{~mm}$ $\mathrm{Hg}$ to a maximum of $200 \mathrm{~mm} \mathrm{Hg}$ or until a leak was visually detected. At each level the pressure was held for 20 seconds. The pressure at which a leak was first observed was recorded.

At the completion of each leak test, staple lines were harvested. The height of each formed stapled was measured and the quality of each formed staple was categorized into one of five descriptive groups (Figure 1). The staple form quality categories were; I. Staple legs touch and form a "B" shape or are below the top of the staple crown, II. Staple legs do not touch, but are not above the crown, III. Staple legs point no more than $45^{\circ}$ away from the crown, IV. Staple legs point more than $45^{\circ}$ away from the crown, and V. Staple legs point more than $90^{\circ}$ away from the crown. Staples in categories III, IV, and V were considered to be malformed staples.

Tissue thicknesses used for each device, luminal leak pressures and staple heights were compared between devices via Student's t-test. Comparisons of rate of leakage at or below $50 \mathrm{~mm} \mathrm{Hg}$ and staple form quality were performed using Fisher's exact test. An alpha of 0.05 was considered to be significant.

\section{Results}

There was no significant difference in the mean tissue thicknesses of samples between GIA and TLC (Table 2). Mean luminal leak pressures were $51.8 \%$ higher for TLC than GIA $(\mathrm{p}<0.001)$, and the proportion of luminal leakage occurring at or below a pressure of $50 \mathrm{~mm} \mathrm{Hg}$ was $81.8 \%$ lower for TLC than GIA ( $\mathrm{p}=0.013$ ). The cumulative proportion of luminal leakage indicates a higher rate of leakage at or below $50 \mathrm{~mm}$ $\mathrm{Hg}$ for GIA, and higher mean leak pressures for TLC (Figure 2).

Mean height of the formed staple was significantly lower for TLC than GIA $(p<0.001)$. No malformed staples were observed for either device, and the distribution of staple forms considered " 1 " or " 2 " were similar.

Supplemental analysis of variance of leakage pressure using device and side as factors and tissue thickness, staple height and staple form as covariates, indicated significance only for device $(\mathrm{p}=0.002)$.

\section{Discussion}

Few studies have made direct comparisons between TLC and GIA staplers. In one evaluation [8], the use of manual suture was compared to use of TLC, GIA and another commercial stapler in gastroenteroanastomosis and enteroanastomosis in swine. No differences were observed between manual suture and any of the staplers for rate of peritonitis, fistula formation, gas leakage, necrosis, stenosis, edema, fibrosis, or granulomatous reaction. Curiously, the abstract states that foreign body granuloma and inflammation were significantly higher with manual suture than stapler, but no evidence for this was presented in the paper. It was noted however that use of staplers was clearly faster than hand suturing, and eliminated the need to open the intestinal wall, thus reducing the risk of contamination within the peritoneal cavity.

In this study, we observed higher leak pressures for TLC compared to GIA and lower staple height, with no difference between the two in terms of malformed staple occurrence. The formed staple height for TLC was $9 \%$ smaller than for GIA, and this might be expected to lead to a tighter, stronger seal. The factor analysis however indicated that the staple height within a device was not a significant driver of leakage pressure, likely because formed staple height was confounded with device. In thicker tissues than were used in this study, both staple height and occurrence of malformed staples may play a more important role. There has been concern that tighter staples might lead to local ischemia, but recent studies have shown that a ratio of closed staple height to tissue thickness of less than 1.0 did not show any evidence of ischemia, whereas hemostasis was improved [9,10] Malformed staples are one of the most frequently occurring mechanisms of staple failure [11] however, in the current study no staples characterized as malformed were observed for either device. This propitious outcome is likely related to the thickness of tissue used; the rate of malformed staples is typically lower for thin than for thick tissue [12].

Both staplers used here incorporated four rows. There has been controversy over whether six-row staplers provide better hemostasis or higher strength [13] but this ex vivo study did not attempt to answer that question. Perioperative hemostasis of course was not assessed and both devices produced leakage pressures that were predominately supraphysiological [14-16].

Preclinical studies have shown that a pre-compression period before staple application is helpful in ensuring proper staple formation, especially in thick tissue $[17,18]$ and decreased bleeding [19]. Likewise in a clinical study, a significant factor for the reduction of risk of anastomotic leakage after low anterior resection was found to be the use of a pre-compression period prior to firing the stapler [20]. Use of pre-compression reduced the odds of leakage by more than a factor of four. It was concluded that both pre-compression and proper cartridge selection were critical for secure stapling and reduced risk of anastomotic leakage. In this study, both devices were used with a 15 -second pre-compression. The IFU for GIA does not recommend a pre-compression waiting period, and hence provides a marginally higher efficiency. This increase in application speed may not provide an overall shorter operative time if it has a negative effect on the strength

Table 2. Summary of Luminal Leak Pressure Comparisons.

\begin{tabular}{|c|c|c|c|}
\hline Measure & $\boldsymbol{G I A}(\mathbf{n = 4 2 )}$ & $\boldsymbol{T L C}(\mathbf{n}=\mathbf{4 2})$ & $\boldsymbol{p}$-value \\
\hline $\begin{array}{c}\text { Tissue Thickness } \\
\text { Mean } \pm \text { St Dev } \\
\text { Range }\end{array}$ & $\begin{array}{c}1.66 \pm 0.19 \mathrm{~mm} \\
1.3-2.0 \mathrm{~mm}\end{array}$ & $\begin{array}{c}1.65 \pm 0.20 \mathrm{~mm} \\
1.3-2.1 \mathrm{~mm}\end{array}$ & 0.786 \\
\hline Leak Pressure & & & \\
Mean \pm St Dev & $83.6 \pm 34.5 \mathrm{~mm} \mathrm{Hg}$ & $126.9 \pm 41.2 \mathrm{~mm} \mathrm{Hg}$ & $<\mathbf{0 . 0 0 1}$ \\
\hline Proportion & & & \\
$\leq 50 \mathrm{~mm} \mathrm{Hg}$ & $11 / 42(26.2 \%)$ & $2 / 42(4.8 \%)$ & $\mathbf{0 . 0 1 3}$ \\
\hline Staple Height & & & \\
Mean \pm St Dev & $1.51 \pm 0.05 \mathrm{~mm}$ & $1.37 \pm 0.04 \mathrm{~mm}$ & $<\mathbf{0 . 0 0 1}$ \\
\hline Staple Form Quality & & & \\
I & $755(97.8 \%)$ & $690(96.8 \%)$ & \\
II & $17(2.2 \%)$ & $23(3.2 \%)$ & 1.000 \\
\hline III, IV, V & $0(0.0 \%)$ & $0(0.0 \%)$ & \\
(Malformed) & &
\end{tabular}




\section{Staple Form Quality Categories}

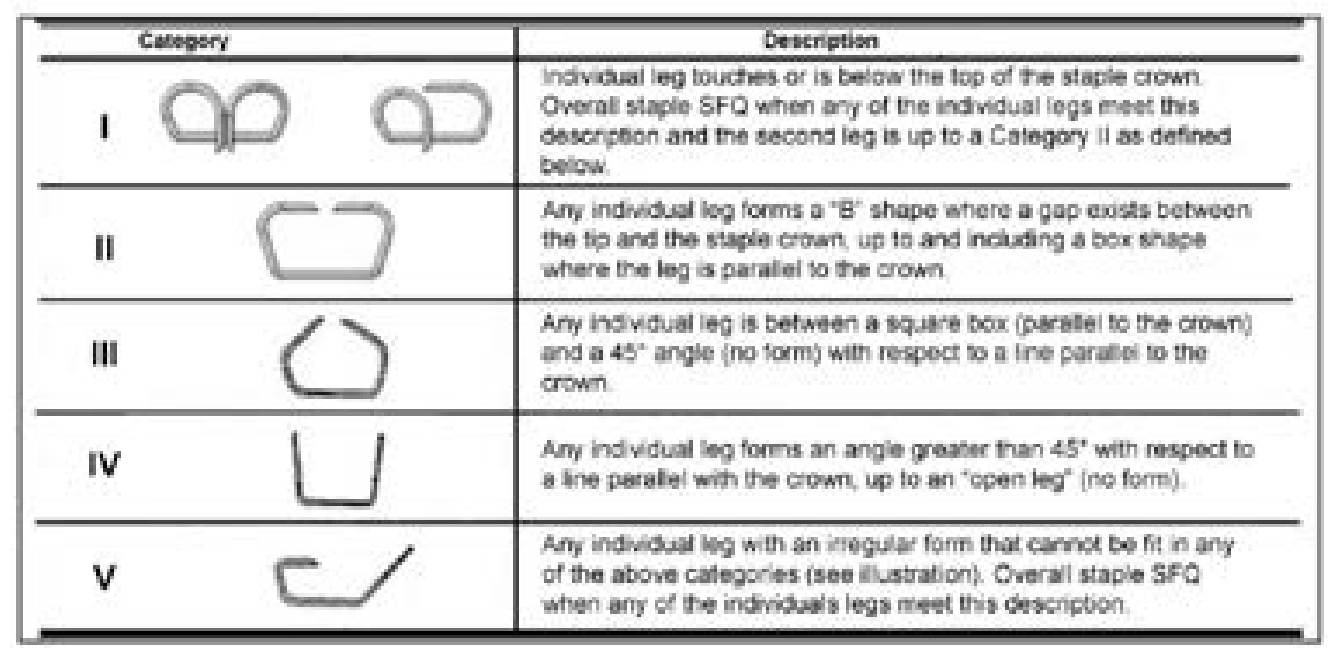

Figure 1. Staple Form Quality Categorization.

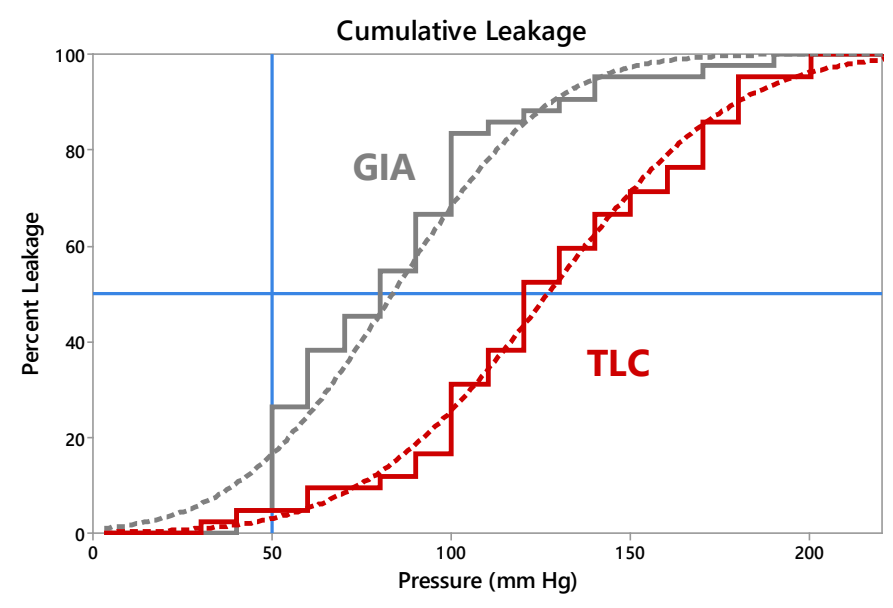

Figure 2. Cumulative proportion of luminal leakage showing a higher rate of leakage at or below $50 \mathrm{~mm} \mathrm{Hg}$ (vertical blue line) for GIA, and higher mean leak pressures (horizontal blue line) for TLC.

of the staple line. Based on the current study, it is not known whether skipping the pre-compression will lead to lower leakage pressures for the GIA device.

Although TLC showed significantly higher leakage pressures than GIA, both devices produced strong seals with mean leakage pressures that were at supraphysiological levels. It could be argued that it does not matter how high a leakage pressure is once it has passed a certain point, since those pressures will rarely be encountered clinically. Using a modern gastrointestinal monitoring system, average pressures in healthy subjects in the colon have been found to be $20.5 \pm 9.99 \mathrm{mmHg}$ [14], while earlier studies using anal manometry indicated $98 \%$ of readings were less than $50 \mathrm{mmHg}$ [15], and there occurred excursions of over $60 \mathrm{~mm} \mathrm{Hg} \mathrm{[16].} \mathrm{We} \mathrm{have} \mathrm{chosen} \mathrm{a} \mathrm{cutoff} \mathrm{of} 50 \mathrm{mmHg}$ to provide a sensitive measure of safety. At this pressure, TLC had significantly fewer leaks than GIA, hence its true clinical success rate is expected to be higher.

In summary, in this ex vivo study we have shown that the TLC linear cutter used as directed, produces tighter formed staples than the
GIA stapler and yields higher luminal leakage pressures from staple lines and fewer leaks at low pressures. Whether this improvement will decrease the rates of anastomotic leakage in actual practice remains to be determined in clinical studies.

\section{References}

1. McGuire J, Wright IC, Leverment JN (1997) Surgical staplers: a review. J R Coll Surg Edinb 42: 1-9. [Crossref]

2. Chadi SA, Fingerhut A, Berho M, DeMeester SR, Fleshman JW, et al. (2016) Emerging Trends in the Etiology, Prevention, and Treatment of Gastrointestinal Anastomotic Leakage. J Gastroint Surg 20: 2035-2051.

3. Schiff A, Brady BL, Ghosh SK, Roy S, Ruetsch C, et al. (2016) Estimated Rate of PostOperative Anastomotic Leak Following Colorectal Resection Surgery: A Systematic Review. J Surg Surgical Res 2: 60-67.

4. Voermans RP, Vergouwe F, Breedveld P, Fockens P, van Berge Henegouwen MI (2011) Comparison of endoscopic closure modalities for standardized colonic perforations in a porcine colon model. Endoscopy 43: 217-222.

5. Kawasaki K, Fujino Y, Kanemitsu K, Goto T, Kamigaki T, et al. (2007) Experimental evaluation of the mechanical strength of stapling techniques. Surgical endoscopy 21: 1796-1799.

6. Coolman BR, Ehrhart N, Pijanowski G, Ehrhart EJ, Coolman SL (2000) Comparison of skin staples with sutures for anastomosis of the small intestine in dogs. Vet Surg 29: 293-302. [Crossref]

7. Elariny H, Gonzalez H, Wang B (2005) Tissue thickness of human stomach measured on excised gastric specimens from obese patients. Surg Technol Intern 14: 119-124.

8. Fernandes MA, Pereira BM, Sandra M, Paganelli A (2014) Randomized clinical trial comparing manual suture and different models of mechanical suture in the mimicking of bariatric surgery in swine. Open Access Surgery 4: 11-18.

9. Myers C, Mutafyan G, Petersen R, Pryor A, Reynolds J, et al. (2009) Real-time probe measurement of tissue oxygenation during gastrointestinal stapling: mucosal ischemia occurs and is not influenced by staple height. Surgical Endoscopy 23: 2345-2350.

10. Abu-Ghanem Y, Meydan C, Segev L, Rubin M, Blumenfeld O, et al. (2016) Gastric Wall Thickness and the Choice of Linear Staples in Laparoscopic Sleeve Gastrectomy: Challenging Conventional Concepts. Obesity Surgery 27: 837-843.

11. Hsi RS, Ojogho ON, Baldwin DD (2009) Analysis of techniques to secure the renal hilum during laparoscopic donor nephrectomy: review of the FDA database. Urology 74: 142-147. [Crossref]

12. Chekan E, Whelan RL (2014) Surgical stapling device-tissue interactions: what surgeons need to know to improve patient outcomes. Medical Devices 7: 305. 
13. Ng CSH, Pickens A, Siegel JM, Clymer JW, Cummings JF (2015) A novel narrow profile articulating powered vascular stapler provides superior access and haemostasis equivalent to conventional devices. Eur J Cardiothorac Surg 49: i73-i78.

14. Maqbool S, Parkman HP, Friedenberg FK (2009) Wireless capsule motility: comparison of the SmartPill ${ }^{\circledR}$ GI monitoring system with scintigraphy for measuring whole gut transit. Dig Dis Sci 54: 2167-2174. [Crossref]

15. Burkitt DS, Donovan IA (1990) Intraluminal pressure adjacent to left colonic anastomoses. Br J Surg 77: 1288-1290. [Crossref]

16. Felt-Bersma R, Gort G, Meuwissen S (1991) Normal values in anal manometry and rectal sensation: a problem of range. Hepatogastroenterology 38: 444-449. [Crossref]
17. Nakayama S, Hasegawa S, Nagayama S, Kato S, Hida K, et al. (2011) The importance of precompression time for secure stapling with a linear stapler. Surg Endosc 25: 2382 2386. [Crossref]

18. Nakayama S, Hasegawa S, Hida K, Kawada K, Sakai Y (2015) Obtaining secure stapling of a double stapling anastomosis. J Surg Res 193: 652-657. [Crossref]

19. Morita K, Maeda N, Kawaoka T, Hiraki S, Kudo A, et al. (2008) Effects of the time interval between clamping and linear stapling for resection of porcine small intestine. Surg Endosc 22: 750-756. [Crossref]

20. Kawada K, Hasegawa S, Hida K, Hirai K, Okoshi K, et al. (2014) Risk factors for anastomotic leakage after laparoscopic low anterior resection with DST anastomosis. Surg Endosc 28: 2988-2995. [Crossref]

Copyright: $@ 2017$ Henninger DD. This is an open-access article distributed under the terms of the Creative Commons Attribution License, which permits unrestricted use, distribution, and reproduction in any medium, provided the original author and source are credited. 